\title{
The Research on Docking Model of Rural Tourism across the Taiwan Straits
}

\author{
Xicong Zheng \\ Tourism Management \\ Minnan Normal University \\ Zhangzhou, China 363000
}

\begin{abstract}
In recent years, rural travel has become a new form of tourism in the industry of China. It is a tourism product developed by the combination of rural and agricultural production and the resource advantages of the countryside, so that the rural industrial economy will show new vitality and realize the sustainable development of rural tourism. This paper analyzes and compares the mode of rural tourism by exploring docking pattern on both sides of the Taiwan Straits, and puts forward some suggestions.
\end{abstract}

Keywords - both sides of the Taiwan Straits; rural tourism; docking pattern

\section{INTRODUCTION}

Rural tourism originated in France in 1855, and has a history of more than 100 years. In the 1960s, rural tourism in the modern sense began in Spain, and then it developed rapidly in developed countries. Until 1980s, the rural tourism began to have the embryonic form as rural level of our country increased gradually. In 1998, the "98 Summer Urban and rural tourism" launched by the National Tourism Administration has made the rural tourism develop rapidly. Compared with other European countries, rural tourism in China started late, but it has been developing towards a more standardized direction in the past 20 years. In recent years, with the rapid development of cross-strait economic and traffic, in Fujian plays an important role for promoting cooperation and docking of rural tourism on both sides of the straits by means of the unique advantages of "Wuyuan". Therefore, the purpose of this paper is to explore cross-strait rural tourism docking and put forward feasible study, which is of great significance for promoting cross-strait rural tourism exchanges and cooperation and industrial structure adjustment and transformation of economic development mode.

\section{OVERVIEW OF RURAL TOURISM}

The concept of rural tourism is not yet fully unified and some typical definitions are as follows: Jansen Verbeke (1991) proposed that rural tourism is all forms of tourism that take place in rural areas.

Lane (1994) believes that rural tourism is not only a tourism activity in rural areas, but a complex and diverse pattern. Among them, rurality is the core and unique point of tourism promotion, and the most basic form of rural tourism should have:

1. Located in a rural area.

2. Village function: It consists of small businesses, open spaces, natural environments, monuments, traditional societies and customs.

3. Village size: Buildings and the environment are small scales.

4. With traditional qualities, slow growth rate, and close relationship with local families.

5. The combination of rural environment, economy, history and location.

The European Union and the World Organization for Economic Cooperation and Development (1994) defined rural tourism as "a tourism activity that takes place in rural areas" and considered that the core of overall promotion of rural tourism is "Rural-tourism".

Oppermann (1996) believes that rural tourism is a sightseeing activity that people continue to perform on nonurban land.

Edmunds (1999) and Reichel, Lowengart \& Miliman (2000) pointed out that the scope of rural tourism may include ecotourism, agrotourism, natural landscape tourism, exploratory tourism or green tourism. It may also contain interesting things such as: food, horse riding, sailing, hunting or other sports, history, cultural tourism, etc.

The study of rural tourism in China began in 1990s and in the early stage, it mainly focuses on tourism development of foreign countries. In the late 1990s, the study of rural tourism content was gradually involved in management, marketing and planning. In recent years, with the rapid development of rural tourism, related research has gradually been paid attention by experts and scholars. According to the statistics, the scholars have defined the concept of rural tourism in their study as follows:

Yao Suying (1997) defined rural tourism as a special tourism product that refers to the rational use of existing resources in rural areas and integration of viewing and shopping habits through scientific planning, design and 
processing, giving tourists choices of enjoying the nature and modern countryside that is not available in the city.

Du Jiang and Xiang Ping (1999) proposed that rural tourism is a relatively novel form of tourism in China, and its market demand will continue to rise with the acceleration of urbanization in China and changes in population structure. However, if there is a lack of scientific understanding and proper handling of the contradiction between supply and demand in the development of rural tourism, the development of rural tourism in China will surely get into trouble.

He Jingming and Li Lihua (2002), defines "rurality" as the most important symbol of rural tourism through the comparison and analysis of existing rural tourism concepts.

Zhou Lingqiang and Huang Zuhui (2004) proposed that rural tourism is a new type of tourism that evolved from the combination of eco-tourism and agricultural tourism. Ecotourism not only includes natural eco-tourism, but also includes humanistic and eco-tourism. The original motive for tourists to choose this type of tourism is the dual return of nature and the ancestral lifestyle.

Guo Huancheng and Han Fei (2010) mentioned in the study that rural tourism is a new industry that is based on agriculture, aims at tourism, uses services as a means, targets urban residents, and combines primary industry and tertiary industry.

Until 2004, experts reached a unified opinion at International Forum on Rural Tourism held in Guizhou that rural tourism in China should include at least the following content: firstly, is to take the unique national folk culture as the soul, to improve the taste and richness of rural tourism; secondly, taking farmers operation as the main body of management, and fully embodies the folk characteristics of "living in farm house, eating farmhouse rice, doing farm work and enjoying family stay"; thirdly, the target market for rural tourism should be mainly positioned as urban residents and satisfy the urban people enjoying the rural scenery and returning to simplicity.

At present, scholars in Taiwan have not yet defined a unified definition of rural tourism. However, this paper sorts out following definitions for the past study:

Zhu Peiying (2002) argued that rural tourism is a kind of sightseeing form, which means that the non-local residents produce leisure and recreational activities by going to nonurban areas and interacting with the local populace to a certain extent, or contacting with the local natural environment, traditional customs, historical culture and agricultural resources.

Tang Xingfen (2005) defines that rural tourism is a kind of sightseeing form, which means non-local residents produce leisure and recreational activities by going to rural areas, and to a certain extent, interacting with local residents (nonspecialized enterprise management, profit-based leisure farm business model), such as catering, shopping, accommodation, etc., and contacting with the local natural environment (the region operated and managed by a non-public sector), traditional customs, living habits, historical culture, and agricultural resources.

Zheng Jianxiong and Shi Xinyi (2007) define that rural tourism is a kind of sightseeing form, which means that nonlocal residents produce leisure and recreational activities by going to non-urban areas, and to a certain extent, interacting with local residents by means of the original natural ecology, agricultural production, rural life and cultural activities.

Liu Jianzhe (2008) proposed that rural tourism refers that tourist engage in leisure and recreation in the overall rural area. The resort area covers the whole countryside and includes a number of villages and fields covered by rural areas.

Xiao Yaojun (2009) pointed out that rural tourism can be called when more than half of the travel itinerary is in the rural areas, and the tourism content may be one of the various industrial types in the rural areas with linking to the local economy and high educative nature.

\section{ANALYSIS ON THE CURRENT SITUATION OF RURAL} TOURISM DEVELOPMENT ON BOTH SIDES OF THE TAIWAN STRAITS

\section{A. Analysis on the Status Quo of Rural Tourism Development in Fujian Province.}

Zeng Zhilan (2012) pointed out in the "Review of the Development of Rural Tourism in Fujian" that rural tourism in Fujian can be divided into several stages such as start-up, rapid development, and planning development and he put forward research views for each stage:

1. Starting stage was situated in 1998-2005. The theme slogan of "98 Summer Urban and rural tourism" and "The colorful life of modern urban and rural" launched by the National Tourism Administration in 1998 has promoted the development of rural tourism in Fujian. Until the beginning of 2006, there were 2 national agricultural tourism demonstration sites in Fujian Province, 4 provincial agricultural tourism demonstration points and nearly 1000 farmhouse resort points. During this period, the financial development of rural tourism in Fujian was just at startup stage and not yet matures.

2. Fast development stage was situated in 2006-2009. In 2006, the National Tourism Administration determined the theme of tourism as "China's rural tourism," and the Fujian Provincial Tourism Administration also determined that the tourism theme in this year was "Tourism in the West Coast of the Taiwan Strait", which aims to demonstrate new countryside, promote new tourism, advocate new experiences, set new trends, and contribute to building new countryside and a harmonious society. Through the work of "Rural tourism on the west side of the Straits ", we should guide agricultural tourism and rural tourism of different types to the development of the characteristic direction, and further improve the rural tourism environment.

In April 2007, the Fujian Provincial People's Government issued the "Notes on Printing and Circulation of Certain Suggestions on Accelerating the Development of Rural Tourism on the West Coast of the Taiwan Strait". Through the development of rural tourism on the western coast of the 
Taiwan Straits, a group of tourist destination of clear themes, convenient transportation, supporting services, beautiful environment and strong attractiveness were gradually formed, which greatly promoted the adjustment of the rural industrial structure and the transformation of the tourism growth mode. In addition, the "5155" plan will be launched during the "Eleventh Five-Year Plan" period to upgrade, cultivate and store 50 small tourism towns, 100 tourism villages, 50 industrial and agricultural tourism demonstration sites, and 50 Grade A tourism areas to enhance rural tourism popularity.

3. From 2010 to today is normative development stage. In 2010, Fujian Province promulgated service quality grade division and assessment (DB35/T 1051-2010) of Fujian Province's rural tourism business unit and the service quality rating assessment and management interim measures of Fujian Province rural tourism business unit, which helped Fujian rural tourism to develop more standard. In the same year, the overall development of rural tourism in Fujian Province was identified as "Rainbow-colored rural Tourism". Each color represents a type of travel location and specifically: Red Tourism mainly refers to the red tour of Western Fujian, and Western Fujian is an important part of the Central Soviet area. It is one of the Red Army's hometowns and the Central Red Army's Long March's starting places. Orange leisure agriculture takes rural ecological pastoral, specialty vegetables, flowers and seedlings, stream and river bank as the main contents.

During the "12th Five-Year" period, Fujian province screened 150 support points for rural tourism, and implemented a project of "one county, one feature and one point, one quality products" to achieve the goal of developing 100 fine rural tourism products. In the "Thirteenth Five-Year Plan" period, Fujian Province will devote itself to the following nine major tasks. It will vigorously promote the structural reform of the tourism supply side and the integration of tourism with other industries and fields. In addition, implementing the cultivation of the leading tourism industry, upgrading the tourism product system, and building brand names of" fresh Fujian" shall be carried out. In the meantime, the province will strive for expanding regional tourism cooperation and deepening Fujian-Taiwan tourism. It's necessary that give full play to the fresh humanity and fresh nature advantages of "fresh Fujian" project and continue to promote the "100 towns and villages" construction project as well as implement tourism-based precise poverty alleviation. All these measures aim to promote the vigorous development of rural tourism.

\section{B. Analysis on the Current Situation of Rural Tourism Development In Taiwan}

The development of rural tourism in Taiwan has been around for more than 40 years. And the development is closely related to the development of agriculture. Lu Xiwen (2015) pointed out in the "Research on Imagery, Satisfaction and Revisiting Will of Rural Tourism - Case Study of Zhongpu Township in Chiayi County" that rural tourism in Taiwan can be divided into start-up period, growth period, vigorous development period and multiple development period etc,. And he put forward its research views for each stage.
1) The budding period of rural tourism development is in the $1960 \mathrm{~s}$

Rural tourism in Taiwan is not a brand new leisure and recreation method. In 1965, the forestry unit developed the Alishan Forest Recreation Area and used multi-functional management methods to develop mountain tourism with combination with agriculture, which was regarded as the startup of formal development of Taiwan rural tourism.

\section{2) The start period of rural tourism is $1970 \mathrm{~s}$}

In the 1970s, the economy of Taiwan region took off. With the development of industry and economy, the status of the primary industry was gradually replaced by the secondary industry, and the status of agriculture suffered declination. Against the background, farmers began to think about agricultural transformation to seek new ways. Due to increased labor costs and increased demand for leisure and recreational markets, farmers began to develop sightseeing orchards. They are mainly engaged in self-employed pattern to have tourist experience leisure activities for fruit picking. However, the early economies were relatively small and there was no enterprise-oriented large-scale operation.

\section{3) The growth period of rural tourism is $1980 \mathrm{~s}$}

With the promotion of paling sightseeing tea garden opened by Taipei Farmers Association in 1980 and the Demonstration Plan of Developing Sightseeing Agriculture approved by the Council of Agriculture of the Executive Yuan in 1982, the sightseeing agricultural garden that provides tourists' leisure and tourism were set up in different parts of Taiwan consecutively, which were popular with farmers and tourists, driving the development of sightseeing and leisure agriculture (Chen Zhaolang, 2005).

However, during this period, the Taiwan Provincial Government began to plan the development of rural tourism, and the Council of Agriculture of the Executive Yuan also proposed in 1983 "the Project of Developing Sightseeing Agriculture Demonstration". At this time, the sightseeing farms in Taiwan mushroomed, and the competition became more intense. In response, all the farms were facing difficulties in business while the original business way was hard to meet the needs of tourists. Therefore, around 1986, the sightseeing farm was gradually transformed into a diversified mode of management, combined with experience, catering and accommodation to provide more services for tourists.

4) The flourishing period of rural tourism was in $1990 \mathrm{~s}$

In 1990, the Taiwan Provincial Council of Agriculture added the "Development of Leisure Agriculture Plan" to the responsible agricultural construction plan and actively guided the development of leisure agriculture. From then on, Taiwan has entered the leisure agriculture era. For the establishment and management of recreational agricultural areas, the "Regional Agricultural Area Management" was promulgated in 1992, which laid down clear guidelines, supervision and reward principles for leisure agriculture. After the 1990s, the development of rural tourism focused on the combination of community development and industrial culture and added the rural, regional and local concepts, allowing rural tourism resources in Taiwan to expand from agricultural resource to rural, regional, and local nature (Tang Xingfen, 2008). Since 
1990s, with the guidance and assistance of the public sector and the promotion of folk units, rural tourism in Taiwan has been developed.

5) The multiple development period of rural tourism is from 2000 to the present

In 2001, the Taiwan Economic Development Association of Executive Yuan announced the "National Tourism Development Program" and the Tourism Bureau of the Ministry of Transport developed a "New Strategy for Tourism Development in Taiwan in the 21st Century", which all emphasized tactics for the development of ecotourism and health tourism.

In addition, in response to the impact of Taiwan's accession to the WTO, the Taiwan Council of Agriculture promoted the "One Township and One Leisure Agriculture and Fisheries Park Project" in 2001 to build rural leisure tourism circles, residential life circles and industrial life circles. In this way, the Taiwan authority aimed to attract travelers and drive rural tourism to flourish. (Agricultural Information Application System of Agriculture Rejuvenation Demonstration,2003).

\section{Analysis of the Current Situation of Rural Tourism Development on Both Sides of the Taiwan Straits}

2010 was a watershed and milestone for rural tourism on both sides of the Taiwan Straits. Prior to this year, rural tourism of the two areas hadn't intense connection. Till 2010, tourism cooperation agreement was signed between Fujian and Taiwan, followed by that the first tourist group of around ten thousand of Fujian folk stepped onto Taiwan, a rural tourism activity, held in Taiwan, creating a precedent for that the mainland organizes rural tourism activities in Taiwan. At the 6th Strait Travel Fair in the same year, 10 villages and towns in Fujian and 10 villages and towns in Taiwan respectively started the negotiation of rural tourism for the first time, and signed the "Declaration on Cooperation between Fujian and Taiwan to Develop Rural Tourism". In July 2012, the Taiwan Rural Tourism Association led the delegation to Fujian for an inspection tour for the first time. The delegation visited and instructed more than 20 rural tourist attractions such as Fuzhou, Xiamen, and Quanzhou.

In 2012, Fujian Province went to Taiwan to carry out special investigations on rural tourism, and the team jointly signed the Agreement on Promoting Rural Tourism Exchange and Cooperation between Fujian and Taiwan. In this agreement, there are five consensuses were reached and they were respectively that: closely interact with each other; build jointly communication channels; compile jointly quality lines, innovate in cooperation platforms, and jointly build intellectual platforms. Moreover, it has been reached more than 10 cooperative projects, for example, the two parties shall carry out mutual reception for the groups visiting each other, promote to launch " $1+1$ "ptoject of rural tourism scenic spots and famous villages and towns, establish jointly the FujianTaiwan Creative Counseling Center of Rural Tourism, and build "Taiwan Training Base for Fujian Rural Tourism Creative Talents", determining the overall framework of rural tourism cooperation between the two sides of the Taiwan Straits.
The 2nd round table meeting of cross-strait rural tourism was held in Xiamen in 2015. Representatives of rural tourism practitioners, managers and researchers from both sides of the Taiwan Strait gathered to share the successful experiences of cross-strait rural tourism development, and to explore of crossstrait rural tourism product system building and the innovative development models.

With the in-depth development of tourism cooperation between the two sides of the Taiwan Straits, the "FujianTaiwan Rural Tourism Test Base" was born. In 2014, Fujian selected four rural tourism key counties - Yongtai, Changtai, Taining and Yongchun and each county had five villages and towns as the "Fujian-Taiwan Rural Tourism Test Base." During the "12th Five-Year Plan" period, according to statistics, Fujian received more than 10 million Taiwan compatriots, and among them, 1.5 million travelers got to Quemoy Island, Matsu Island and Penghu Island and Taiwan islands via Fujian ports. Up to now, the subject plan of tourism development in Fujian "Thirteenth Five-Year Plan" has proposed that Fujian will strengthen cross-Straits interconnection and interoperability in the next five years, deepen tourism cooperation between Fujian and Taiwan, and promote Fujian to become a pilot pre-test area for cross-strait tourism cooperation policies, preferred travel destinations and transit locations of cross-Strait's visitors, showing that the cross-strait exchanges has been booming.

\section{THE CONSTRUCTION OF DOCKING MODE OF RURAL TOURISM ON BOTH SIDES OF THE STRAIT}

\section{A. Docking Model Based on Geopolitical Characteristics}

In Fujian Province's special tourism development plan in "13th Five-Year Plan", it is proposed to deepen tourism cooperation between Fujian and Taiwan and strive for full coverage of the "Individual Tour" pilot cities in Taiwan. In the meantime, the province will spare no effort to build a "golden channel" on the water and focus on building a "Channel Strait Cruise" tourist route between Fujian, Taiwan Hong Kong and Macaw. Fujian has the closest distance between the mainland and Taiwan province with its unique advantages of "five lucks". What's more, the unmatched "low-level three links" between Xiamen and Quemoy have become the most convenient golden channel for cross-strait personnel exchanges. So, Fujian has unparalleled geographic advantages for the rural tourism exchange between the two sides of the Strait, and if we can make full use of these superiorities, the rural tourism economy on both sides of the Strait is bond to be greatly encouraged.

\section{B. Docking Mode Based on Technical Guidance}

After 40 years of development, rural tourism in Taiwan has accumulated considerable experience. It not only achieves scale, but also has cultural characteristics. However, although rural tourism in Fujian Province has also been progressing for 20 years, it is still in the developing stage in some regions. According to rural tourism experts and workers on both sides of the Taiwan Straits, in response to the dilemma of cross-strait rural tourism development, providing technical guidance for 
the management of rural tourism on both sides of the Strait is helpful for improving its overall development.

\section{Docking Mode Based on Network Platform}

Through the construction of the rural tourism network platform, the traditional rural tourism activities can be launched into the Internet and the platform can include government agencies, rural tourism associations, e-commerce service providers, etc. The integration of resources on the Internet platform makes it possible that provide any information and services related to rural tourism, so that people on both sides of the Taiwan Strait can use this platform to collect relevant information and plan out personalized rural tourism.

\section{The Docking Mode Based on the Rural Tourism Industry on Both Sides of the Strait}

The dockings and exchanges between rural tourism institutions on both sides of the Taiwan Strait not only help promote deep industry cooperation, but also have a positive effect on the exchange of technology and talents. Through learning from each other's experiences in the development of rural tourism, the two sides jointly discussed new ways of creative development of rural tourism industry, drive the development of rural tourism-related industries, and form the linkage effect of "one industry encourages one industry; one industry promotes hundreds of industries", finally achieving innovation and development continuity of rural tourism products.

\section{CONCLUSION}

In order to implement the docking model of rural tourism across the Taiwan straits, the biggest difficulty lies in whether the government and people can cooperate with each other with eliminating the political and economic factors. If we can coordinate and deal with the practical difficulties, it will effectively promote the development of cross-strait rural tourism and create a win-win situation of cross-strait rural tourism.

\section{REFERENCES}

[1] JansenVerbeke,M.Towards balanced tourism development in Europe.Nijmegen:University of Nijmegen. 1991.

[2] Bernard Lane. What is rural tourism?[J]. Journal of Sustainable Tourism, 1994, 2(1):7-21.

[3] Oppermann M. Rural tourism in southern Germany.[J]. Annals of Tourism Research, 1996, 23(1):86-102.

[4] Edmunds, M. Rural tourism in Europe [J].Travel and Tourism Analyst, 1999,6(1):37-50.

[5] Reichel A, Lowengart O, Milman A. Rural tourism in Israel: service quality and orientation.[J]. Tourism Management, 2000, 21(5):451-459.

[6] Jiang Du, Ping Xiang. Thinking on the sustainable development of rural tourism[J].Tourism Tribune, 1999, 14(1):15-18.

[7] Huancheng Guo, Fei Han. A Summary of the Development of Rural Tourism in China[J].Progress in Geography, 2010, 29(12):1597-1605.

[8] Suying Yao. A Brief Talk on Rural Tourism[J].Journal of Beijing International Studies University, 1997(3):42-46.
[9] Jingming He, Luhua Li. Discussion on the Concept of "Rural Tourism"[J].Journal of Southwest University(social science edition), 2002, 28(5):125-128.

[10] Lingqiang Zhou, Zuhui Huang. Study on Problems and Countermeasures of Sustainable Development of Rural Tourism in China[J]. Economic Geography, 2004, 24(4):572-576.

[11] Peiying Zhu. A Study on the Motivation, Expectation and Satisfaction of Tourists Engaged in Rural Tourism: A Case Study of Hsinchu County[J]. Master's thesis of Tourism Research Institute of Shih Hsin University, 2002.

[12] Xingfen Tang. The social impact of Rural Tourism - an analysis of the influence of local residents' perception and attitude[J]. Outdoor Recreation Research, 2005, 18:73-96.

[13] Jianxiong Zheng. New Villagerism and Development of Rural Tourism[J]. Rural Tourism Research, 2007, 1(2):1-17.

[14] Jianzhe Liu. Rural Tourism and Rural Development Policy[J]. Rural Tourism Research, 2008, 2(2):1-10.

[15] Yaojun Xiao. The key element of Sustainable Rural Ecotourism -- a case of Bach Ha and Peach[J]. Master's thesis of Ecotourism Institute of National University of Tainan, 2009.

[16] Zhilan Zeng. A Review of the Development of Fujian Rural Tourism[J].Issues of Forestry Economics, 2012, 32(6):552-555.

[17] Xiwen Lv. Research on Imagery, Satisfaction and Revisiting Will of Rural Tourism: A Case Study of Zhongpu Township in Chiayi County[J]. Master's thesis of Department of Tourism Management of University of South China, ,2015. 